\title{
Sustainable Corporate Social Responsibility In The New Normal Era And The Principal-Agent Problem
}

\author{
Muhammad Baqir ${ }^{1}$ and Gu Biao ${ }^{2}$ \\ \{m.baqir86@gmail.com¹ ${ }^{1}$ gubiao2000@gmail.com ${ }^{2}$ \}
}

Shanghai University, 99-Shangda Raod, Shanghai, China ${ }^{12}$

\begin{abstract}
The ethical standpoint of Sustainable Corporate Social Responsibility (SCSR) amid Covid-19, considering the principal-agent problem, is the objective of this study. According to the best of the knowledge of this author, there have not much been written about this problem. This paper is a summary of the definitions and explanation of the SCSR, business ethics, social contract, principal-agent problem, and a review conclusion based on the main literature available in hand. This paper's literature survey studies the controversies that managers face while implementing SCSR, especially in times of the new normal, by the firm that they operate and decides for. The legitimacy and philosophy of SCSR practices are based on business ethics. The steps in between them are the reality of the principal-agent problem, the legitimacy through Social Contract Theory. Thus, the social contract provides legitimacy for business ethics and business ethics makes foundations for SCSR. This dire need, through this contribution, has been fulfilled to a primary literature survey that connects the dots between the points.
\end{abstract}

Keywords: Covid-19, Principle-Agent Problem, Social Contract Theory, Sustainable CSR

\section{Introduction}

The principal-Agent problem is a much-discussed and debated issue. The main idea it holds is that a party's actions influence the outcomes that affect the second party, given that the earlier is supposed to work for them later. Let's say the principal, assume in a firm the owner, and the agent (in this case the manager) have different intentions following the incentives in their lives by the activities of the firm. Moreover, the actions of the agent are always unobservable to the principal, which arises the stated problem due to the asymmetric information [12]. The asymmetric information is that the perfect information is not equally distributed and to get the perfect information either becomes impossible or time and resource costs. Here we can take the example of the insurance company and the person being insured, the insurer has no information on how the insured person is living and caring about their life. The 
main thing that a business is looking for is the amount of risk-sharing that these two parties (the manager and the owner) have [36]. The phenomenon of asymmetric information arises in a firm due to many reasons and to be short and relevant one of the reasons is the magnitude of the involvement in the firm's some activity. This concept can be well understood by a simple example that if person A buys some used item from person $\mathrm{B}$, then it is for sure that person $\mathrm{B}$ has more information about the item that they have been owning for some time. As person A has never owned this particular item, they have no perfect information about the internal condition and working capability of this used item. In the same sense, the manager is daily involved in the activities of the firm such as decision making and market conditions. While less or no involvement of the shareholders in such activities, at least on daily basis, arises the fact of asymmetric information between the agent and the principal.

This research work through step by step procedure discusses the phenomena of the principal-agent problem, the social contract theory, the business ethics, and the legitimacy of Sustainable Corporate Social Responsibility (SCSR). The dire need of establishing a connection between the principle-agent problem and the SCSR is fulfilled through this primary literature survey that connects the dots between the points. The conclusion of this paper is comprised of the findings of the selected literature on the principle-agent problem and SCSR.

\section{Literature Review}

Sustainable Corporate Social Responsibility (SCSR) is, besides evolving concept in business and management, is discussed by many business researchers since its emergence [1], [2]. Most of the researches has been worked on mainly its impact on the overall revenue of the firm. The main contributions hold that in the long run, the firms practicing SCSR tend to gain higher sales revenues, while the firms without SCSR practices would be earning more in the short run. This research will shortly discuss this part of the issue in detail. According to my humble knowledge, most of the left researches focus on the main issue of the manager has the ethical and legal position to decide on the SCSR activities to be performed and their frequency and magnitude [15], [3], [4]. Followings are the step by step categorical parts of the issue under discussion:

\section{The Principal-Agent Problem}

As introduced earlier this problem can be understood when we take into account the roles played by the principal and the agent. There are certain assumptions made. The principal cannot monitor every decision made by the agent, yet the 
outcome can affect the principal. The agent has the right to decide on any action plan inside the firm authorized fully by the principal. The principal and the manager have different incentives. From now this work takes the owner of the firm as principal and the manager as an agent. Thus to have the agent work as if they were the principal we have to introduce the optimal incentive scheme. These incentive plans are two types, one in which the increased revenues tend to provide the manager a pay increase, and in the second type an increase always happens as a percentage of the increased revenues [4].

The stronger assumption that cannot be violated in this case is that the agent is the only agent in its character it does not own any single shares of the company otherwise the phenomenon of the pure agency will collapse. This assumption is important here because the CEOs of the current multinational companies tend to have 15\%-25\% shares of their companies (and even the sole entrepreneurs) thus mitigating the problem of the principal-agent in such a way that this higher ratio of ownership tends to make them the principals working as agents and in this way the problem vanishes itself [18], [23].

The assumption of the asymmetric information is important in the regard that it distinguishes the principal and agent when it comes to the availability of the information for data processing and decision making.

\section{Business Ethics as the foundation of SCSR}

SCSR, why and how, is answered by the fact of business ethics. Business ethics is the set of codes that determine the activities and actions that can be distinguished to be right or wrong. Thus the decisions made by the firm will have the criteria of right and wrong, that is, depends on the business ethics defined for the firm regarding the environment that it operates in [14], [36], [41]. The basic issue of the principal-agent problem just starts arising here as a question of who, the principal, or the agent, will be deciding to set the business codes of ethics? And by setting such codes and following upon such codes, who may be benefiting the most and who can be accounted for the faults?

Windsor [39] is of the view about two aspects of the corporate citizenship language that leads to the different point of views arising the Sustainable Corporate Social Responsibility, one is the instrumental aspect that says if the firm exercises the SCSR and can increase the level of its revenues (stated by the proxies of market opportunities and firm's goodwill) then the manager can have discretionary power in deciding so. 


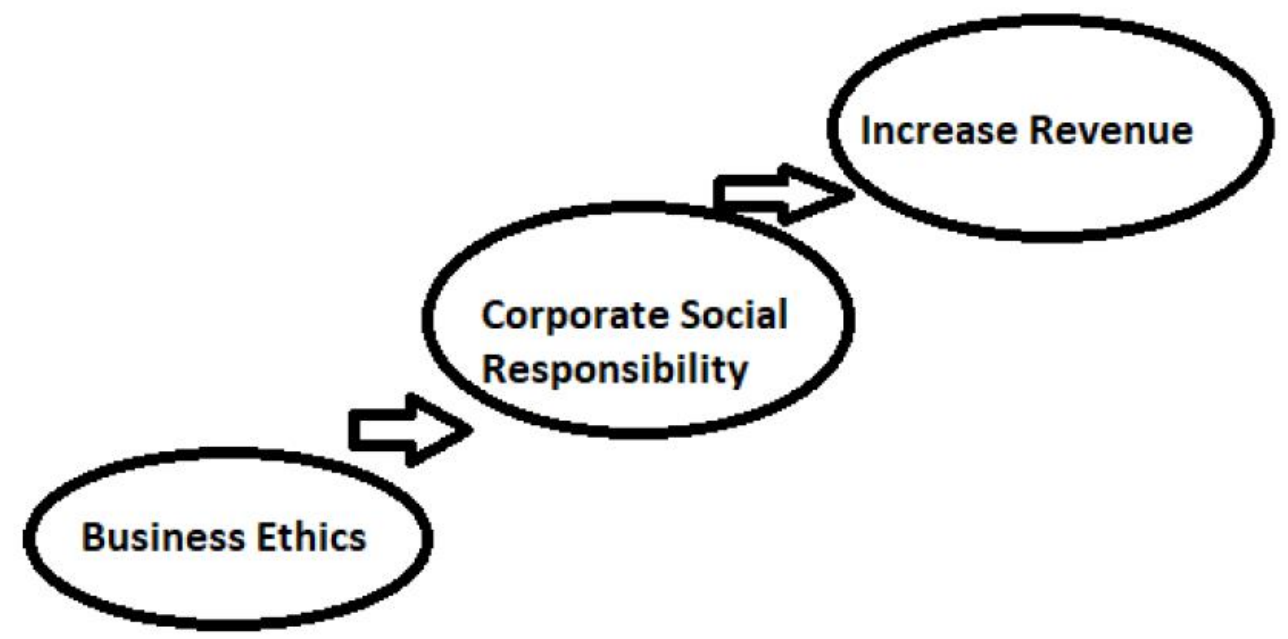

Fig. 1. The ladder to profits

Figure 1 depicts that business ethics is connected to higher revenues through corporate social responsibility. The second aspect as the ideal citizenship in the sense of the volunteerism language states that the humanitarian SCSR will affect the manager's decisions at the human rights level. This phenomenon leads to Milton Friedman's criteria of 3 for a manager to practice SCSR, which can be summarized as;

1. The SCSR practices must obey the laws

2. The SCSR practices must be profitable

3. The SCSR practices must be ethical

This Shareholder Theory or the Stakeholder Theory is also called the Friedman Paradigm which, as stated above, is an economic way of discussing the SCSR given that it only takes into consideration the monetary (revenues and profits) into account and it does not take the role of business ethics as important as the business researchers do. While Post [32] is his critique of this approach to SCSR, views that this approach is in its way mistaken in terms that it belongs to the persons qualified in a branch of science that deals with every aspect as monetary, that is, Economics.

While some of the researchers have proposed an assumption to solve the principal-agent problem in a way that the agent perfectly decides for the good of the principal. This idea can be also convincing as the agent is hired for the same reason, has the job description, and has shared benefits with the principal [15], [22]. 32], [41].

Swanson [38] found that the firm's Corporate Financial Performance is directly related to the SCSR activities. This is as the manager entrenches the account of the earning management linking it to the SCSR account so that the stakeholders' 
activism could be avoided and maintain the manager's position in the firm. Their recommendations infer that the firm's more spending in SCSR cannot be overseen as it also links to the bad performance of the firm's financial performance, which is indeed tax reductions and tends to indulge in inefficient SCSR practices.

Pava and Krausz [27] have discussed an issue on the specific criteria on which the managers are entitled to practice SCSR, given that SCSR always contains costs. They proposed 4 basic criteria as i) the need for the SCSR in locality ii) the level of the responsibility that the firm can take iii) consensus from the shareholders and iv) the SCSR practice's impact on the financial performance of the firm.

While Surroca and Tribó [37] have discussed the tightening of the principalagent problem in the age of the financial crisis of 2007-09. Where there rose a debate on the agents' role and the dilemma of their interest conflicts with the principals. It emphasizes the SCSR in the tightening financial scenario. The reliance is on the banking sector of the Dutch banks and their questionable role in SCSR at the time of the financial crisis. The authors found that the managers of the stated banks wanted as many profits to be earned in the shortest time possible thus turning their banks into "casino". The authors propose that the full technology be replaced with the quasi technology so that the newly defined ethical grounds be applied, and evaluated by humans, to refrain from the inefficient application of the SCSR [28].

When it comes to the size of the enterprise and the principal-agent problem Hetherington [19] stated that the size does not matter and the problem roots in the economic phenomena of the self-interest of the agent, while this issue can only be resolved if the principal works as an entrepreneur in their firm.

While discussing the legitimacy of the SCSR practices of the firm to be linked with the interests of the principals, there are also some researches on the SCSR and its relationship with Corporate Financial Performance (CFP), measuring the SCSR as Corporate Social Performance (CSP) [5], [6], [13]. They base their research on the notion of Milton Friedman [13] which is that a firm can enter some activities as long as it is compatible with the long-run increase in its profits. If so then the incentives of both managers and the stakeholders are matched and there would be no problem with the principal-agent.

Friedman [13] has also been criticized for its only-monetary view of the firm's responsibility. For instance, Lantos [22] after breaking down SCSR in its four components (originally proposed by Carroll in 2000) such as economic, legal, ethical, and altruistic, attacks Friedman's profit-driven firm theory.

The economic responsibility of the firm is to create jobs, create profit, and uplift the living standard of the people in the firm. While the legal responsibility of 
the firm is to obey and operate following the laws that it operates in. The ethical responsibility of the firm is to refrain from harming society, respecting society, and be moral and ethical in its activities be they inside or outside the firm. Today, all the firms if not practically, they admit it theoretically that ethical responsibility is the ethical SCSR. And yes the controversy starts with the fourth component that is the altruistic responsibility also known as Carroll's philanthropy concept. It can be described as a set of volunteer activities such as volunteer giving, volunteer service, and formation of volunteer associations [22].

Lantos [22] also proposes Andrew Carnegie's biblical approach to SCSR as a classic twofold statement in favor of SCSR being the first as the charity principle and the stewardship responsibility. Both of these statements are common to say as the person, and also the firm, are the fortunate ones in the society have liability to uplift the unfortunate ones in the society, may they be persons or firms.

On the other hand, Gray et al., [16] were of the point of view that the reporting of the SCSR is way controversial than that of the financial reporting. Furthermore, the researchers have found, to be as simplistic as possible, four different aspects of literature for the legitimacy of the SCSR. They named them the extreme rights, extreme lefts, the status quo proponents, and the defenders of the intellectual property rights [17], [36].

\section{The Social Contract Theory}

The review of the literature helps us in understanding the main foundations of the SCSR after the inclusion of the business ethics into account, which for sure is the theory of the social contract for the firms. The roots having in philosophy and politics, social contract theory has developed to take part in every part of the science and especially the business and management with the sub-area of the SCSR [26].

Keeping it as all simple, as William H. Bennett said in Lincoln Douglas [20] Debate at the University of Vermont, the social contract is the main reason why does a government ever exists. The set of rules that cover the relationship and the nature of the relationship between the public and their government is defined for the social contract. The terms of responsibilities and rights that the public owe to the government and the rights and the responsibilities that the government may expect from its public are all the aspects of the human society that social contract covers.

Manning [23] has stated that the debate in SCSR has been of two types, namely Rhetorical arguments, and Eristic Arguments. The rhetorical argument is stated 
to be as persuasive to influence the idea to hold valid. While the Eristic argument is thought to be the set of arguments to disprove the initially stated argument. At the very base of the SCSR, we have to differentiate between business morality and business ethics. Business or personal morality is defined as the set of beliefs or values that are strongly held and shared amongst the society members [23]. While, on the other hand, business or personal ethics is regarded as the values or justifications for the right and virtuous deeds and behaviors inside the society or business environment.

While the ethical theories to the SCSR tend to fall in the following 4 aspects;

1) The Instrumental SCSR theories focus on economic and accounting objectives by implementing social activities.

2) Political SCSR theories focus on the business' power inside the political scenario.

3) The Integrative SCSR theories focus on fulfilling, to a possible extent, the social needs and demands through the firm's management.

4) The Ethical SCSR theories focus on doing a virtuous deed inside the society for the betterment.

In the light of literature, it is also doubted that the multinational corporations whose economic power is greater than that of many nations specifically developing nations tend to play politics in the nations. This manipulation of power goes straight against the legal bindings of the firms. One such example can be described as the firms competing for being a monopoly, the larger firms tend to attain comparative advantages by the means of political driven SCSR activities.

Another aspect arises when it comes to the measurement of the SCSR practices' outcomes, which is called Corporate Social Performance. This measure is necessary so that the stakeholder may come upon the impact made by the cost incurred for the SCSR activity [27]. It is to be also noted that the criteria made by the stakeholders may arise a trade-off to that of made by the managers for the planning, implementing, and measuring the scope of the SCSR activities by the firm. The sustainability of the business environment and keeping the firm profitable be it in the short run or the long runs are prime objectives of both stakeholders and the firm managers.

The triple bottom line concept given by John Elkington in the 1990s is also known as the 3Ps of sustainability, namely Planet, People, and Profit. It is stated that decades of reasoning for a social contract in business and research has established the good foundations of the legitimacy of SCSR through being an ethically responsible firm inside society.

As stated earlier the social contract deals with the reasoning of the justification or condemnation of a government, the business and management researchers 
(business ethicists and/ or the normative philosophers) have used the social contract philosophy and reasoning to explore the relationship of the firm/ business and the society [25], [29].

Swanson [38] ( in his book has an interesting chapter, "the longitudinal classification of Sustainable Corporate Social Responsibility", where he discusses the three SCSR concept-development stages based on the logical reasoning of the business ethicists and normative researchers/ philosophers. First are the decades of the 1950s and 1960s the time of the corporate social stewardship. The idea of the stewardship principle is that the managers have to see themselves as the guardians of the resources that society owns collectively by nature [7], [11]. Thus it also gave birth to the charity principle that now it is also the responsibility of the winners of the business to work upon the betterment of society. When it comes to the collective consciousness, it is the idea that the rise and fall of the firms and society are so interconnected that they have a mutual conscious indeed.

The second era of the 1960s to 1970 s corporate social responsiveness. This phenomenon firm's response to the social pressure to work for the betterment of society. And such laws made in this era on economic responsibility of the firm entangled with the social and environmental responsibilities which undermined the triple bottom line [8], [16], [38].

The third era has been of corporate/ business ethics in the 1980s and 1990s. Increasing corporate responsiveness to the social benefits and legislation in this regard in favor of the firm's social responsibility took the firms to go through the fact. And this was the age when business ethics was to be defined and streamline the business ethics of the firms. The nomination of the values and organizational environment and organizational culture were in fact with no controversy for most of the businesses and the firms [32].

Post-1990s is the era of the SCR and society research that mainly has broadspectrum attention to the environmental degradation caused by the firms and their stakeholders. And here is where the SDGs (Sustainable Development Goals) and 5Ps (People, Planet, Prosperity, Partnership, and Peace) are born. 


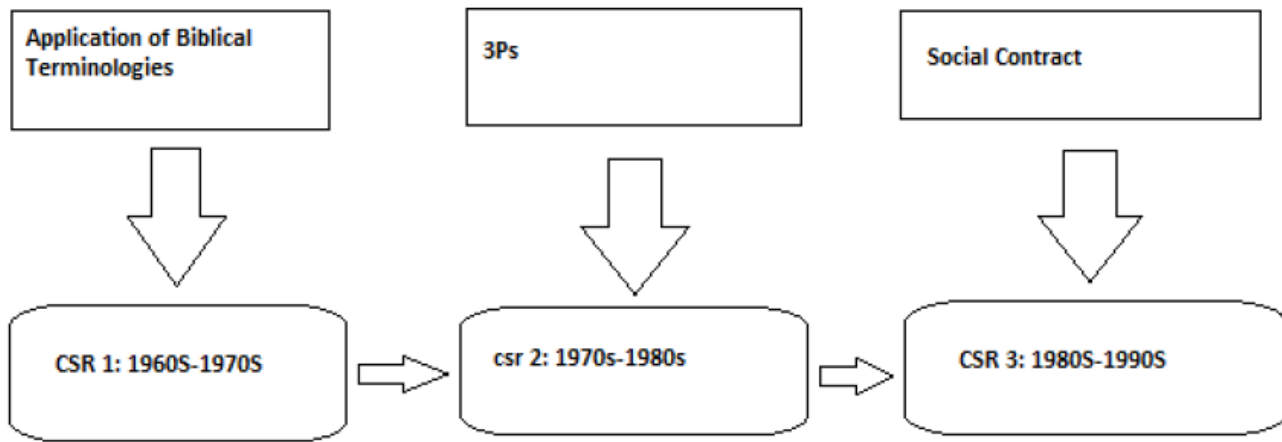

Fig. 2. The evolution of the concept of legitimacy for CSR

Figure 2 portrays the stages in the history of the legitimacy of CSR in some recent times. Though the principal-agent problem may be seen as solved but it has roots in what the stakeholders today are of common opinion. That is the stakeholders agree that the restoration of the environment is not only the firm's social responsibility but also of the other stakeholders, namely consumers, shareholders, government, etc. But on every new issue, let's suppose the problem of the waste management especially the electronic waste management, the stakeholders take apart from their consensus of who mainly is responsible or/ and who must play the role more than the other counterpart always remains the bone of contention and yes as has been decades ago the main player between all these disagreements and debates is Principal-Agent Problem. This reasoning is that principals at the end of the day are the general public [19], [31].

\section{The Sustainable Corporate Social Responsibility}

Moir [25] suggests that Sustainable Corporate Social Responsibility, even if it does not have a common definition, may be generalized as the firm's good role in society by both being profitably efficient and socially beneficial. Thus SCSR is a continuation of the commitment of the firm towards the betterment of the employees, stakeholders, consumers, and its better quality (and environmentally friendly) products in particular and the society in general [9], [10], [37].

Barrios, Fasan, and Nanda [3] defined SCSR as the set of decisions that businessmen are obliged to take which could be in line with the objectives and values of the society. The main criticism of such a definition is that this is a very generalized definition and rises many controversies as it keeps the distinguishing and identification of such decisions and values and objectives of the society purely on the manager [20], [35]. this issue has been raised by many business researchers as well as practitioners. Beaudoin [4] advocated the same in his work, but it could also be stated that such a definition only can be of some 
firm's legitimacy of operating in society rather than being a socially responsible corporation/ business.

Jamali and Karam [21] found that the national business system in developing nations plays an essential role in defining and describing the SCSR. The basic work of the authors was to explore the different definitions of the SCSR based on the characteristics that different developing nations possess. Though it was previously assumed that they may have been the same as the developing nations have many of the similar characteristics. Thus the fact is that besides the similar characteristics of the developing nations, the difference of the business, and other relevant factors. And the national business system plays a vital role among them all [21], [34].

Matten and Moon [24] have proposed that instead of keeping SCSR's definition as vague or different in different regions, let's make it generalize by keeping all definitions in one place. And the differences in the definitions though arise from the different aspects such as political, financial, educational \& social systems, and some internal variables such as the size of the firm, organization, market, and coordination and control systems.

Suchman [36] has a thorough study of the legitimacy of the SCSR with a different spectrum. Those are the three organizational legitimacy approaches namely the moral, cognitive, and pragmatic approaches and they face three types of problems in the organization and they are as gaining, maintaining, and repairing such legitimacy [24], [30]. Lindblom (1994, cited in Gray et al., 1996) proposes four-fold steps to be taken namely, educating the stakeholders on decisions made, being made, and going to be made by the firm for a particular event.

Windsor [40] has put some light on the future of the SCSR, having in mind the works of the opponents of the legitimacy of an ethical SCSR available in the body of research knowledge. The author is of the point of view that till the 1990s the research literature and the pedagogical materials have been of two mainly loose things that did not overlap to some acceptable major points. This issue has been elaborated in the author's paper and is considered to be one of the early standpoints $n$ such a topic. Also, the future of the SCSR in the increasing role of globalization makes a new forefront of the research field to explore and discuss [39], [40].

Carroll [8] has also questioned whether SCSR can be used as a marketing tool for the increase in revenues and they check this fact through consumer reaction and found a weak relationship. They concluded that a weak and positive relationship holds there for SCSR and the firm's increased revenues. This fact was depicted here to align with Friedman's version of SCSR, just discussed earlier [23], [33]. 


\section{Literature Findings}

Sustainable Corporate Social Responsibility has been debated for long decades and mainly for its legitimacy. The main issue the researchers and philosophers have been discussing is the principal-agent problem. To back the legitimacy of the SCSR, there have been so many thoughts and logical reasonings associated with each timeline.

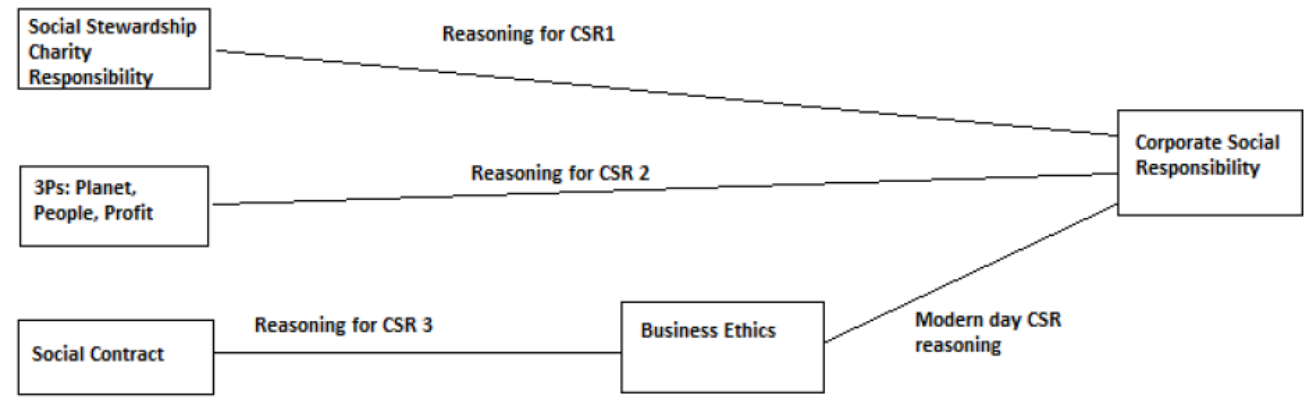

Fig. 3: The Reasonings for CSR's legitimacy

Figure 3 presents the main three reasons for CSR in literature, with the third one identified by the authors which have been neglected by the practitioners and researchers.

From the biblical philosophies of social stewardship and charity to the 3Ps of the planet, people, and profit and from that point to the social contract theory. There has been a collective stance on social responsibility, through the introduction of some elements/ dimensions in the Sustainable Development Goals (SDGs) and 5Ps (People, Planet, Prosperity, Partnership, and Peace) by the United Nations.

While the legitimacy of the SCSR practices is now backed by "The Social Contract Theory". This theory as discussed earlier defines the relationship between the two parties in the society, and to be on its preliminary point, it deals with the criteria set to maintain the relationships, responsibilities, and rights of the public and their government. The same theory later applied to the SCSR practices as a firm is a party operating in the society and it is an entity inside the society so there must be rules, and criteria, to define the relationships, responsibilities, and rights of the firm/ business and the society. Thus, through the social contract theory, it stood legitimate for the firm operating in society to put in its contribution to the wellbeing of the society as well. Thus this theory eliminated the principal-agent problem, as the primary social responsibility of the principal and the agent became homogeneous. Yet, it is important to discuss here is that for a particular issue raised by economic activity, the question still 
in consideration among the researchers, academicians, and business community with stakeholders is that who will be responsible and to what extent a specific party among the stakeholders has to play a role? In short, SCSR is evolving and is on a voyage of changing paradigms as time passes and critiques being overcome.

Thus to summarize, the conceptual framework gives a timeline of the literature the research questions asked, during different phases of the research work on SCSR. The first reasoning was derived from the biblical philosophy of social stewardship of an owner/rich or investor to build up the lower class in the society and it was termed as fortunate ones moving up the unfortunate ones. After a decade of research the legislation for the triple bottom line was introduced, as 3Ps of Planet, People, and Profit, which became a moral rationale behind the SCSR activities.

And at last, the theory of the social contract was applied to the firms to redefine the role of the firm in society. This application of the theory of the social contract gave strong foundations for the business ethics that lead to the reasoning of the SCSR to be valid, ethical, and moral.

Here the research paper will not refrain to mention that Friedman's approach to the SCSR practices to be only the profit-driven and revenue-impacting activities is one of the major critiques of the current SCSR's reasoning through the social contract theory forwarded by the corporate ethics. Further quantitative work on corporate social performance is needed, which will yield broader and vivid conclusions related to the discussion among the researchers on the legitimacy and efficacy of the SCSR.

\section{Conclusion}

Corporate Social Responsibility (CSR) has been researched in recent decades. Recently Sustainable Corporate Social Responsibility (SCSR) has been opted for the studies by researchers across the globe. This study sheds light on the legitimization of the SCSR in the face of the current pandemic. It went through many controversies while defining its existence to its implementation and reporting. One of those controversies was the principal-agent problem. This paper is an attempt to look up to the history of the debate on SCSR having in mind the Principal-Agent Problem. And in the year 2020 when the Covid-19 has hit and the SCSR by the larger profitable firms is much needed. The gradual progress of this literature survey is from the roots of the principal-agent problem, the logic behind this terminology, the social contract as logical reasoning for the business ethics, and the development of the reasoning for the 
legitimacy of the SCSR practices. Thus the literature survey takes from 1958 to 2019 the latest literature available.

This research finds that business ethics, forwarded by the social contract phenomenon, has played a vital role in mitigating the concept of the principalagent problem in SCSR practices. Once the manager and the stakeholders are on a single page of corporate ethics (which includes the external and internal ethics and responsibilities) there remains no controversy of why or why not the agent spends on SCSR.

There can be more of an empirical analysis on this issue, while the nature of the study and the data and variables are up to the researchers ahead. While to be honest and open, there is also a dire need for sound empirical analysis to see the SCSR and CSP be positively and maybe strongly correlated. This work will or these researches will eliminate the issue raised by Friedman's economicspecific SCSR's legitimacy. In such a way that a profitable SCSR does not cross out the boundary (which is the firm's first and main objective is to earn a profit) set by Friedman. And answers to the questions such as who has to play more or less role in some certain issues? These all such questions remain open to future researches. 
Acknowledgments. I am thankful for the Chinese Government Scholarship, the authority which is funding my master's studies at Shanghai University. I am also grateful to Professor Wang Hong (Shanghai University) for her valuable comments on this study. 


\section{References}

[1] Adda G, Azigwe JB, Awuni AR. Business ethics and corporate social responsibility for business success and growth. European Journal of Business and Innovation Research. 2016;4(6):26-42.

[2] Aguinis H, Villamor I, Gabriel KP. Understanding employee responses to COVID-19: a behavioral corporate social responsibility perspective. Management Research: Journal of the Iberoamerican Academy of Management. 2020 Aug 12.

[3] Barrios JM, Fasan M, Nanda D. Is corporate social responsibility an agency problem? Evidence from CEO turnovers. Evidence from CEO Turnovers (December 1, 2014). 2014 Dec 1.

[4] Beaudoin CA. Earnings management: The role of the agency problem and corporate social responsibility.

[5] Bennett, W. The Social Contract A Lincoln Douglas Debate Introduction, University of Vermount. Available from:

[6] Brammer S, Millington A. Does it pay to be different? An analysis of the relationship between corporate social and financial performance. Strategic management journal. 2008 Dec;29(12):132543.

[7] Carroll AB. Ethical challenges for business in the new millennium: Corporate social responsibility and models of management morality. Business Ethics Quarterly. 2000 Jan 1:33-42.

[8] Carroll AB. Sustaibable Corporate Social Responsibility. Organizational dynamics, 2015 Jan 1; 44(2):87-96.

[9] Carroll AB. The pyramid of corporate social responsibility: Toward the moral management of organizational stakeholders. Business horizons. 1991 Jul 1;34(4):39-48.

[10] Caulfield PA. The evolution of strategic corporate social responsibility. EuroMed Journal of Business. 2013 Sep 13;8(3):220-42.

[11] Delbard O. Corporate social responsibility beyond philanthropy? Sustainable and responsible business in times of Covid-19. Managing a Post-Covid19 Era. 2020 May:258.

[12] Dodd Jr EM. For whom are corporate managers trustees. Harv. L. Rev.. 1931;45:1145.

[13] Friedman M. The social responsibility of business is to increase its profits. InCorporate ethics and corporate governance 2007 (pp. 173-178). Springer, Berlin, Heidelberg.

[14] Friedman M. The social responsibility of business is to increase its profits. InCorporate ethics and corporate governance 2007 (pp. 173-178). Springer, Berlin, Heidelberg.

[15] Goel M, Ramanathan PE. Business ethics and Corporate Social Responsibility-Is there a dividing line. Procedia Economics and Finance. 2014 Jan 1;11(1):49-59.

[16] Gray R, Owen D, Maunders K. Corporate social reporting: emerging trends in accountability and the social contract. Accounting, Auditing \& Accountability Journal. 1988 Jan 1;1(1):6-20.

[17] Grossman, S, \& Hart, O. An analysis of the principal-agent problem. Econometrica: Journal of the Econometric Society, 1983 Jan 1; 45(7).

[18] He H, Harris L. The Impact of Covid-19 Pandemic on Corporate Social Responsibility and Marketing Philosophy. Journal of Business Research. 2020 May 21.

[19] Hetherington JA. Fact and legal theory: Shareholders, managers, and corporate social responsibility. Stan. L. Rev.. 1968;21:248.

[20] https://debate.uvm.edu/NFL/rostrumlibld.html [Accessed 18 August 2020]

[21] Jamali D, Karam C. Corporate social responsibility in developing countries as an emerging field of study. International Journal of Management Reviews. 2018 Jan;20(1):32-61.

[22] Lantos GP. The boundaries of strategic corporate social responsibility. Journal of consumer marketing. 2001 Dec 1.

[23] Manning L. Corporate social responsibility. InFood ethics education 2018 (pp. 121-146). Springer, Cham.

[24] Matten D, Moon J. Corporate social responsibility. Journal of business Ethics. 2004 Dec 1;54(4):32337. 
[25] Moir L. What do we mean by corporate social responsibility?. Corporate Governance: The international journal of business in society. 2001 Jun 1.

[26] Orlitzky M. The politics of corporate social responsibility or: why Milton Friedman has been right all along. Annals in Social Responsibility. 2015 Jun 8.

[27] Pava ML, Krausz J. Criteria for evaluating the legitimacy of corporate social responsibility. Journal of Business Ethics. 1997 Feb 1;16(3):337-47.

[28] Petersen HG, Wiegelmann AM. Risk Taking, Principal Agent Problems and Breakdown of Corporate Social Responsibility (CSR): How to Reestablish Safe-Assets and Capital Funding for Social Security?. Equilibrium. Quarterly Journal of Economics and Economic Policy. 2013;8(2):7-30.

[29] Petersen HG, Wiegelmann AM. Risk Taking, Principal Agent Problems and Breakdown of Corporate Social Responsibility (CSR): How to Reestablish Safe-Assets and Capital Funding for Social Security?. Equilibrium. Quarterly Journal of Economics and Economic Policy. 2013;8(2):7-30.

[30] Porter ME, Kramer MR. The link between competitive advantage and corporate social responsibility. Harvard business review. 2006 Dec;84(12):78-92.

[31] Post FR. A response to "the social responsibility of corporate management: a classical critique". American Journal of Business. 2003 Apr 22.

[32] Prior D, Surroca J, Tribó JA. Are socially responsible managers really ethical? Exploring the relationship between earnings management and corporate social responsibility. corporate governance: An international review. 2008 May;16(3):160-77.

[33] Sannikov Y. A continuous-time version of the principal-agent problem. The Review of Economic Studies. 2008 Jul 1;75(3):957-84.

[34] Sen S, Bhattacharya CB. Does doing good always lead to doing better? Consumer reactions to corporate social responsibility. Journal of marketing Research. 2001 May;38(2):225-43.

[35] Sen S, Bhattacharya CB. Does doing good always lead to doing better? Consumer reactions to corporate social responsibility. Journal of marketing Research. 2001 May;38(2):225-43.

[36] Suchman MC. Managing legitimacy: Strategic and institutional approaches. Academy of management review. 1995 Jul 1;20(3):571-610.

[37] Surroca J, Tribó JA. Managerial entrenchment and corporate social performance. Journal of Business Finance \& Accounting. 2008 Jun;35(5-6):748-89.

[38] Swanson DL. CSR discovery leadership: Society, science and shared value consciousness. Springer; 2017 Aug 3.

[39] Windsor D. Corporate social responsibility: Three key approaches. Journal of management studies. 2006 Jan;43(1):93-114.

[40] Windsor D. The future of corporate social responsibility. International Journal of Organizational Analysis. 2001 Jan 1;9(3):225-56.

[41] Young SL, Makhija MV. Firms' corporate social responsibility behavior: An integration of institutional and profit maximization approaches. Journal of International Business Studies. 2014 Aug 1;45(6):670-98. 